\title{
Comparisons of 7- to 78-joint ultrasonography scores: all different joint combinations show equal response to adalimumab treatment in patients with rheumatoid arthritis
}

\author{
Hilde Berner Hammer ${ }^{*}$ and Tore K Kvien
}

\begin{abstract}
Introduction: The primary objectives were to explore the associations between a comprehensive ultrasonographic (US) assessment of joints, tendons and bursae and previously described reduced joint counts (7-, 12-, 28- and 44joint score) as well as to assess the sensitivity to change of these different US joint combinations during biological treatment.

Methods: Twenty patients with rheumatoid arthritis (RA) were examined by US (B-mode (BM) and power Doppler (PD)) with use of a semi-quantitative (0 to 3 ) score of 78 joints, 36 tendons/tendon groups and two bursae (hereafter described as the 78-joint score) at baseline and 1,3,6 and 12 months after initiating treatment with adalimumab. BM and PD scores for the different joint combinations were generated.

Results: The reduced joint scores had high correlation coefficients with the 78-joint score at all examinations (range 0.79 to 0.99 for $\mathrm{BM}$ and 0.77 to 0.99 for PD, each $P<0.001$ ) and sum BM and PD scores of all the different joint combinations improved significantly during follow-up ( $P \leq 0.05$ to 0.001$)$.

Conclusions: The reduced joint combinations were highly associated to the 78-joint score. Furthermore, all the joint combinations presently explored responded well to biological treatment. This indicates that an approach focusing on few joints and tendons gives equivalent information about the inflammatory activity in RA patients as a comprehensive US examination. The optimal combination of joints and tendons for a valid, reliable and feasible US measurement should be further explored to define a US score for follow-up of RA patients on biological treatment.
\end{abstract}

\section{Introduction}

Ultrasonography (US) is increasingly used for evaluation of synovitis in patients with inflammatory joint diseases, and synovitis and effusion are detected by grey scale (Bmode, BM) and vascularization by use of power Doppler (PD) [1]. US is a validated and reliable method for assessing joint inflammation [2-5] and it is sensitive to change during treatment with biological medication [5-8]. Different joint combinations have been proposed for optimal and/or feasible assessments of joint inflammation in patients with rheumatoid arthritis (RA). The

\footnotetext{
*Correspondence: hbham@online.no

Department of Rheumatology, Diakonhjemmet Hospital, Diakonveien 12, 0370 Oslo, Norway
}

7-joint score by Backhaus et al. [9] was evaluated in a longitudinal multicenter German study and found to reflect disease activity and therapeutic response. Naredo et al. [10] developed from a 44-joint score in a multicenter Spanish study a 12 -joint score that was useful in monitoring the response to biological medications. Another 44-joint score was used by Scirè et al. [11] and a 28-joint US score assessing the joints included in the composite DAS28 score [12] has been used in longitudinal and cross-sectional studies $[3,5,13]$. We have recently shown that US assessment of 78 joints also was sensitive to change during adalimumab treatment [14]. Thus, several joint combinations have been demonstrated to be useful in the assessment of RA patients,

\section{Biomed Central}


but further work is needed to identify the optimal combinations of joints for therapeutic assessment. In addition, tenosynovitis is a frequent pathology in RA patients and both US and MRI assessments have been shown to be responsive $[15,16]$ and thus evaluation of tenosynovitis may be considered for inclusion in an optimal US score.

The objectives of the present longitudinal study of RA patients were to assess the associations between a comprehensive US score (including 78 joints, 36 tendons and 2 bursae) and existing reduced scores of 7-, 12-, 28and 44-joints and to explore the responsiveness of the various joint scores during biological treatment.

\section{Materials and methods}

A comprehensive US assessment of joints, tendons and bursae was performed in 20 patients with RA [17] (median (range) age 53 (21 to 78) years, disease duration 7.5 (1 to 26) years, 15 women, $70 \%$ IgM rheumatoid factor positive). US assessments of the 78 joints in these patients were previously described [14] as well as the wrist- and ankle tendon assessments [15]. In addition, the patients were examined bilaterally for tenosynovitis in the long biceps tendon and for inflammation in subdeltoid bursa. The patients were consecutively included the same day as they started treatment with adalimumab (40 mg every other week) as their first biological medication. All patients also received methotrexate and 14 patients used additionally prednisolone (median range dose: 7.5 (3.75 to 15$) \mathrm{mg}$ per day). US examinations were performed by one experienced sonographer $(\mathrm{HBH})$ at baseline and after 1, 3, 6 and 12 months with use of a 5 to $13 \mathrm{MHz}$ probe (Siemens Antares, Sonoline, Siemens Medical Solutions, 1230 Shorebird Way Mountain View, CA, USA) and fixed settings (PD with frequency $7.3 \mathrm{MHz}$ and pulse repetitive frequency $391 \mathrm{~Hz}$ ) [18]. The same machine and setting (without upgrading) was used throughout the study. The following joints were assessed bilaterally by use of standard longitudinal projections (scanning positions in parenthesis) [19]: proximal interphalangeal (PIP) 1 to 5 (dorsal), metacarpophalangeal (MCP) 1 to 5 (dorsal), carpometacarpal (CMC) 1 to 5 (CMC 1 radial/palmar, CMC 2 to 5 dorsal), wrist (each of the radiocarpal, intercarpal and radioulnar joints) (dorsal), elbow (anterior, lateral and posterior), shoulder (glenohumeral, with scanning dorsal transverse with maximal external rotation of the arm and acromioclavicular joints with longitudinal scanning), hip (anterior), knee (suprapatellar and lateral), ankle (talocrural joint) (anterior), four major foot joints (talonavicular, calcaneocuboidal, cuneonavicular, subtalar) (anterior and lateral), tarsometatarsal 1 to 5 (dorsal), metatarsophalangeal (MTP) 1 to 5 (dorsal) and the interphalangeal (dorsal) joint of the first toe (a total of
78 joints) [14]. In addition, tendons were examined bilaterally by use of definitions as described by OMERACT [1]. The extensor tendons of the wrists were assessed at the level of the radiocarpal joint and the examination included tendons of all six compartments: abductor pollicis longus and extensor pollicis brevis; extensor carpi radialis brevis and longus; extensor pollicis longus; extensor digitorum and extensor indicis; extensor digiti minimi; extensor carpi ulnaris. At the palmar side, three flexor tendons/groups were examined bilaterally at the level of the radiocarpal joint; flexor pollicis longus, flexor carpi radialis and combined flexor digitorum superficialis and profundus. In the ankles, eight tendons were assessed bilaterally: peroneus longus and brevis (behind the lateral malleol), extensor digitorum longus, extensor hallucis longus and tibialis anterior (anterior at the level of the distal tibia), tibialis posterior, flexor digitorum longus and flexor hallucis longus (behind the medial malleol) [15]. The long biceps tendon (anterior) was also examined, and thus a total of 36 tendons/tendon groups were evaluated. All tendons were assessed transversely by moving the probe proximally and then distally along the tendons and finally longitudinally by moving the probe medially and laterally over the tendon/tendon groups. In addition, potential abnormalities in subdeltoid bursa were explored bilaterally by use of a transverse scan at the level of tuberculum major, and the size and PD activity were evaluated using additionally scans, as required. The joints, tendons and bursae were scored for BM (presence of synovitis and joint fluid) and PD (presence of vascularization) as score $0=$ none, score $1=$ minor, score 2 = moderate or score $3=$ major presence.

All US examinations were performed in one room in the morning, after at least half an hour of acclimatization to room temperature [20]. The pressure of the probe was as low as possible to obtain optimal PD signals. The hands and fingers were assessed while resting on a small table, the elbows were examined in extension and flexion, the shoulders with the patient sitting and the lower limbs were examined with the patient lying on a bench. The US examiner was blinded for previous US results as well as for the results from clinical and laboratory examinations the same day.

Reliability tests for US scoring of joints were performed on acquired images with median (range) intraobserver intraclass correlation coefficients (95\% CI) of 0.97 (0.96 to 0.98 ) for BM scores and 0.98 (0.97 to $0.99)$ for PD scores [14]. No reliability tests were, however, performed for the scoring of tendons and bursae.

With the BM or PD scores from the comprehensive assessment of 78 joints, 36 tendons or tendon groups and 2 bursae (hereafter called the 78-joint score) as basis, sum scores of BM or PD for the different joint 
combinations/joint scores were computed. The 7 -joint score by Backhaus et al. includes examination of the wrist, MCP 2 and 3, PIP 2 and 3, and MTP 2 and 5 at the clinically dominant side with assessment of synovitis, paratenonitis/tenosynovitis and erosions [9]. However, neither examination of flexor tenosynovitis in the second and third finger nor assessments of erosions were performed in this study, and joints and tendons on the patients right side were presently defined as being the dominant side and included in the calculations of the 7 joint score. The original 7-joint score includes assessment of BM synovitis in MCP 2 and 3 only from the palmar view, paratenonitis/tenosynovitis from both dorsal and palmar aspect, and PD assessments on both palmar and dorsal aspect of these joints. The PIP two and three joints were in the 7-joint score assessed for synovitis only on the palmar aspect while PD assessments were performed both at dorsal and palmar side. In our study only dorsal scans were performed on MCP and PIP joints and thus these scores were included in the present calculations. The wrist was in the 78-joint score examined as the radiocarpal, intercarpal and radioulnar joints separately, and the sum of these scores was included as the wrist-assessment in the 7-joint score. The tendons described as dorsal and ulnar part of the wrist in the 7-joint score were in this study defined as compartment 4 and 6 of the extensor tendons, and the palmar tendons were defined as the superficial and deep flexor tendons, and they were all included in the sum 7 joint score.

The 12-joint score by Naredo et al. [10] includes bilateral examination of the elbow, wrist, MCP 2 and 3, knee and ankle in addition to the medial and lateral tendon compartments in the ankle. In the original 12-joint score the wrist was described as the dorsal carpal recess, which was presently defined as the radiocarpal and intercarpal joints. Except for both palmar and dorsal evaluation of MCP 2 and 3 joints in the 12-joint score, the scannings of joints and tendons were similar to the 78-joint score.

The 28-joint score $[5,13]$ includes the same 28 joints as used in the DAS28 score [12] with bilateral examination of the glenohumeral joint, elbow, wrist, MCP 1 to 5 , PIP 1 to 5 and knee with similar scanning method as used in the 78-joint score. However, since the wrist score was not clearly defined, the highest score of the radiocarpal, intercarpal and radioulnar joints was used in this study for the calculation of sum scores for BM and PD of these 28 joints.

The 44-joint score by Naredo et al. [10] includes the glenohumeral joint, elbow, wrist, MCP 1 to 5, PIP 1 to 5 , hip, knee, ankle, midtarsal joints and MTP 1 to 5 joints. From the 78-joint score we used the highest score of the three wrist joints and the highest score of the midtarsal joints for the calculations of the 44-joint score. In addition, the 44-joint score includes the biceps, dorsal and palmar wrist tendons, medial, anterior and lateral ankle tendons as well as the subdeltoid bursae. Thus all these tendons and bursae were included in the present calculations. Table 1 displays an overview of the joints, tendons and bursae included in the different reduced joint scores.

The patients gave written consent according to the Declaration of Helsinki, and the study was approved by the local ethics committee (the regional committee for medical and health research ethics (REK), South-East).

\section{Statistics}

Wilcoxon signed rank test was used to examine changes in US sum scores during follow-up for the different joint combinations. Associations between the sum scores of BM or PD of the comprehensive joint score and the different reduced joint combinations (described in Table 1) were assessed by use of Spearman's rank correlations. A $P$-value $<0.05$ was considered statistically significant. Responsiveness was visualized by use of simple error bar plots with $95 \%$ confidence interval.

\section{Results}

PIP3, MCP 1 and 2, CMC1, radiocarpal- and radioulnar joints, MTP 1, 2, 3 and 5 were inflamed $(B M \geq 1)$ at one or both sides in $\geq 50 \%$ of the patients at baseline. High BM scores (2 or 3) were found in MCP 1 and 2, CMC1, radiocarpal- and radioulnar joints, MTP 1, 2 and 3 at one or both sides in $\geq 40 \%$ of the patients and high PD activity (score 2 or 3 ) was detected in MCP 1, 2 and

Table 1 The joints, tendons and bursae included in the 7, 12-, 28- and 44-joint scores

\begin{tabular}{|c|c|}
\hline $\begin{array}{l}\text { Reduced joint } \\
\text { score }\end{array}$ & Joints, tendons and bursae included \\
\hline 7-joint score [9] & $\begin{array}{l}\text { On the clinically dominant side: } \\
\text { Wrist, MCP } 2 \text { and } 3 \text {, PIP } 2 \text { and } 3 \text {, MTP } 2 \text { and } 5 \\
\text { Dorsal, ulnar and palmar tendon sheaths of the wrist, } \\
\text { flexor tendon sheaths of } 2 \text { and } 3 \text { finger, } \\
\text { paratendonitis dorsal } 2 \text { and } 3 \text { finger }\end{array}$ \\
\hline $\begin{array}{l}\text { 12-joint score } \\
{[10]}\end{array}$ & $\begin{array}{l}\text { Bilateral examination of: } \\
\text { Elbow, wrist, MCP } 2 \text { and 3, knee and ankle } \\
\text { Medial and lateral tendon sheaths of the ankle }\end{array}$ \\
\hline $\begin{array}{l}\text { 28-joint score } \\
{[12]}\end{array}$ & $\begin{array}{l}\text { Bilateral examination of: } \\
\text { Shoulder (glenohumeral), elbow, wrist, MCP } 1 \text { to } 5 \text {, PIP } \\
1 \text { to } 5 \text { and knee }\end{array}$ \\
\hline $\begin{array}{l}\text { 44-joint score } \\
{[10]}\end{array}$ & $\begin{array}{l}\text { Bilateral examination of: } \\
\text { Shoulder (glenohumeral), elbow, wrist, MCP } 1 \text { to 5, PIP } \\
1 \text { to 5, hip, knee, ankle, mid-tarsal, MTP } 1 \text { to } 5 \\
\text { Biceps tendon sheath, extensor and flexor tendons } \\
\text { sheaths of the wrist, flexor tendons sheaths of the } \\
\text { fingers, anterior, medial and lateral tendon sheaths of } \\
\text { the ankle } \\
\text { Subdeltoid bursa }\end{array}$ \\
\hline
\end{tabular}

MCP, metacarpo-phalangeal joint; PIP, proximal inter-phalangeal joint; MTP, metatarso-phalangeal joint 
5, CMC1, radiocarpal- and radioulnar joints, MTP 2 and 5 at one or both sides in at least $30 \%$ of the patients. Thus, all the different joint combinations include most of the joints which were found to be frequently inflamed.

High correlations were found between the sum BM 78-joint score and all of the different joint combinations, with median (range) correlation coefficients at the five examinations of 0.89 (0.86 to 0.96) for BM 7-joint score, 0.86 (0.79 to 0.96 ) for BM 12-joint score, 0.95 (0.92 to 0.97 ) for BM 28-joint score and 0.97 (0.95 to 0.99) for BM 44-joint score (each $P<0.001$ ). High correlations were also found between the sum PD 78-joint score and all of the joint combinations with median (range) 0.85 (0.80 to 0.95 ) for PD 7-joint score, 0.81 (0.77 to 0.90) for PD 12-joint score, 0.93 (0.89 to 0.95$)$ for PD 28-joint score and 0.98 (0.95 to 0.99 ) for PD 44-joint score (each $P<0.001)$. Tables 2 and 3 show the correlation coefficients between all the joint combinations at baseline and at the 12-month follow-up.

All the joint combinations showed significant improvement in sum scores of BM and PD during treatment (Tables 4 and 5), which is illustrated by use of error bar plots of the sum BM or PD scores at all examinations (Figure 1). In particular, the more comprehensive joint counts did not seem to have superior responsiveness compared to the counts with inclusion of fewer joints/tendons.

\section{Discussion}

To our knowledge the present longitudinal study with examinations of a large number of joints, tendons and bursae is the most comprehensive US assessment published so far. During biological treatment the US scores based on a reduced number of joints and tendons were found to have high correlations with the comprehensive score at all examinations and to provide comparable information to the comprehensive score regarding responsiveness. In addition, we found that the most

Table 2 Correlation coefficients between sum scores Bmode (BM) of the different joint combinations

\begin{tabular}{lllll}
\hline & $\begin{array}{l}\text { BM 12-joint } \\
\text { score }\end{array}$ & $\begin{array}{l}\text { BM 28-joint } \\
\text { score }\end{array}$ & $\begin{array}{l}\text { BM 44-joint } \\
\text { score }\end{array}$ & $\begin{array}{l}\text { BM 78-joint } \\
\text { score }\end{array}$ \\
\hline $\begin{array}{l}\text { BM 7-joint } \\
\text { score }\end{array}$ & $0.87 / \mathbf{0 . 9 2}$ & $0.86 / \mathbf{0 . 8 9}$ & $0.85 / \mathbf{0 . 9 1}$ & $0.87 / \mathbf{0 . 9 3}$ \\
$\begin{array}{l}\text { BM 12-joint } \\
\text { score }\end{array}$ & $0.84 / \mathbf{0 . 9 3}$ & $0.86 / \mathbf{0 . 9 6}$ & $0.87 / 0.96$ \\
$\begin{array}{l}\text { BM 28-joint } \\
\text { score }\end{array}$ & & $0.94 / \mathbf{0 . 9 3}$ & $0.95 / \mathbf{0 . 9 3}$ \\
$\begin{array}{l}\text { BM 44-joint } \\
\text { score }\end{array}$ & & & \\
\hline
\end{tabular}

Spearman's rank correlation coefficients between sum scores BM of the different joint combinations at baseline and at 12 months follow-up (in bold italics) $(P<0.001$ for all the correlations).
Table 3 Correlation coefficients between sum scores power Doppler (PD) of the different joint combinations

\begin{tabular}{lllll}
\hline & $\begin{array}{l}\text { PD 12-joint } \\
\text { score }\end{array}$ & $\begin{array}{l}\text { PD 28-joint } \\
\text { score }\end{array}$ & $\begin{array}{l}\text { PD 44-joint } \\
\text { score }\end{array}$ & $\begin{array}{l}\text { PD 78-joint } \\
\text { score }\end{array}$ \\
\hline $\begin{array}{l}\text { PD 7-joint } \\
\text { Score }\end{array}$ & $0.89 / \mathbf{0 . 8 9}$ & $0.92 / 0.94$ & $0.94 / 0.93$ & $0.95 / 0.95$ \\
$\begin{array}{l}\text { PD 12-joint } \\
\text { Score }\end{array}$ & & $0.81 / 0.85$ & $0.86 / 0.85$ & $0.86 / 0.89$ \\
$\begin{array}{l}\text { PD 28-joint } \\
\text { Score }\end{array}$ & & & $0.94 / 0.95$ & $0.93 / 0.95$ \\
$\begin{array}{l}\text { PD 44-joint } \\
\text { score }\end{array}$ & & & \\
\hline
\end{tabular}

Spearman's rank correlation coefficients between sum scores PD of the different joint combinations at baseline and at 12 months follow-up (in bold italics) $(P<0.001$ for all the correlations).

frequently inflamed joints with high degrees of BM and PD pathology were included in the described reduced joint counts. The CMC 1 joint, however, is often involved in osteoarthritis $[21,22]$ and this joint may not be useful for evaluation of RA activity. This joint is also not considered in the new ACR/EULAR classification criteria for RA [23].

The present US assessments of joints and tendons were slightly different from some of the reduced joint scores. The most important difference was the scanning method of MCP and PIP joints, where the 7-joint score assesses both the palmar and dorsal side, while only dorsal assessments were performed in the 78-joint score. There is so far no consensus on which side of these finger joints US examinations give the most sensitive and/ or reliable results, but up to now the majority of studies have assessed the dorsal part of the finger joints.

The PD scores in the 78-joint examination were defined as none, minor, moderate or major presence of PD activity. The PD scoring in the reduced joint scores were slightly different and performed as described by Szkudlarek et al. [24,25] who define score 2 or 3 as a PD signal covering less or more than $50 \%$ of the synovitis area. However, it may be difficult to differentiate between these scores since most machines do not have programs defining a certain percentage of PD activity relative to grey scale pathology.

The various scores that are explored in this study have been evaluated in longitudinal studies and are found to detect improvement during biological medication. So far, most evaluations of response to treatment have been performed by use of the patient's evaluations, clinical examinations and laboratory assessments, and with presentation of composite scores that reflect inflammatory activity [12,26-28], in accordance with the published EULAR/ACR recommendations [29]. US has in previous studies been found to be a valid and reliable examination for assessment of synovitis as well as the degree of vascularization (by use of PD activity) [2-5]. Since the 
Table 4 Sum B-mode (BM) scores of the different joint combinations during the study

\begin{tabular}{llllll}
\hline & Baseline & $\mathbf{1}$ month & $\mathbf{3}$ months & 6 monhts & $\mathbf{1 2}$ months \\
\hline 7-joint score & $11.5(1$ to 22$)$ & $7.5(0 \text { to } 20)^{*}$ & $6.5(0 \text { to } 15)^{*}$ & $7.0(0 \text { to } 17)^{* *}$ & $5.5(0 \text { to } 16)^{* *}$ \\
12-joint score & $15.0(0$ to 52$)$ & $12.5(0 \text { to } 37)^{*}$ & $11.0(0 \text { to } 28)^{*}$ & $9.5(0 \text { to } 32)^{*}$ & $7.5(0 \text { to } 28)^{*}$ \\
28-joint score & $17.0(2$ to 65$)$ & $13.0(2 \text { to } 57)^{* *}$ & $11.0(0 \text { to } 45)^{* *}$ & $8.5(1 \text { to } 45)^{*}$ & $12.0(0 \text { to } 45)^{*}$ \\
44-joint score & $40.0(6$ to 131$)$ & $31.5(3 \text { to } 103)^{* *}$ & $29.5(6 \text { to } 71)^{* *}$ & $19.5(1 \text { to } 69)^{* *}$ & $20.0(1 \text { to } 73)^{* *}$ \\
78-joint score & $53.5(6$ to 154$)$ & $38.5(3 \text { to } 124)^{* *}$ & $36.5(6 \text { to } 96)^{* *}$ & $23.5(1 \text { to } 91)^{* *}$ & $27.0(1 \text { to } 101)^{* *}$ \\
\hline
\end{tabular}

Sum BM scores of the different joint combinations at baseline and after 1, 3, 6 and 12 months. All joint combinations showed significant change from baseline ${ }^{*}$ $\left.=P \leq 0.05,{ }^{* *}=P \leq 0.001\right)$.

Table 5 Sum power Doppler (PD) scores of the different joint combinations during the study

\begin{tabular}{|c|c|c|c|c|c|}
\hline & Baseline & 1 month & 3 months & 6 monhts & 12 months \\
\hline 7-joint score & 8.0 (0 to 19$)$ & $5.0(0 \text { to } 17)^{*}$ & $3.5(0 \text { to } 13)^{*}$ & $2.0(0 \text { to } 12)^{* *}$ & $2.5(0 \text { to } 12)^{* *}$ \\
\hline 12-joint score & 9.0 (0 to 42 ) & $8.0(0$ to 31$)$ & $6.5(0 \text { to } 26)^{* *}$ & $6.0(0 \text { to } 29)^{*}$ & $3.0(0 \text { to } 29)^{*}$ \\
\hline 28-joint score & 10.5 (0 to 50$)$ & $8.0(0 \text { to } 34)^{*}$ & $3.5(0 \text { to } 28)^{* *}$ & $3.5(0 \text { to } 35)^{* *}$ & $4.0(0 \text { to } 35)^{*}$ \\
\hline 44-joint score & 26.5 (1 to 96$)$ & $17.0(0 \text { to } 63)^{* *}$ & $11.5(1 \text { to } 38)^{* *}$ & $12.0(0 \text { to } 63)^{* *}$ & $9.5(0 \text { to } 73)^{* *}$ \\
\hline 78-joint score & 33.0 (1 to 119$)$ & $21.0(0 \text { to } 83)^{* *}$ & $15.5(2 \text { to } 52)^{* *}$ & $13.5(0 \text { to } 82)^{* *}$ & $12.5(0 \text { to } 81)^{* *}$ \\
\hline
\end{tabular}

Sum PD scores of the different joint combinations at baseline and after 1, 3, 6 and 12 months. All joint combinations showed significant change from baseline ${ }^{*}$ $\left.=P \leq 0.05,{ }^{* *}=P \leq 0.001\right)$.

primary goal for RA management is to suppress the inflammation to a level that prevents disability and joint destruction [30], US may be an additional promising clinical tool for evaluation of response to treatment and level of inflammatory activity. However, to make US a feasible method in the clinical setting, it is of major importance to explore the lowest number of joints and tendons that is able to give information about the inflammatory process in most of the patients. The present study indicates that assessment of as few as seven joints and five tendons/tendon compartments is sensitive to change and with high correlations to the comprehensive joint and tendon assessment. The inclusion of a few tendons is supported by a recent study where the extensor carpi ulnaris and tibialis posterior tendons were found to be most frequently inflamed and with US scoring of these tendons being highly sensitive to improvement during treatment [15]. Thus further studies ought to be performed to identify the joints and tendons that should be included in a limited US score.

In a study of RA patients in clinical as well as ACR and DAS28 remission, the majority of patients had US evidence of inflammation when eight joints were assessed (dominant hand MCP 2 to 5 and four wrist joints) [31]. Thus, this low number of joints was able to detect ongoing pathology in spite of normal combined clinical and laboratory composite scores. In the search for an optimal combination of joints and tendons for US scoring of RA patients, this scoring system should also be explored for its sensitivity to evaluate US remission in RA patients.
The strength of the present study is the performance of a comprehensive joint, tendon and bursae assessment by only one experienced sonographer in a longitudinal design during anti-TNF treatment, use of standardized US assessments utilizing the same machine throughout the study and no missing examinations. However, an obvious weakness is the low number of participating patients. For this reason we were not able to use the dataset to identify a new US joint combination with high trade-off between feasibility and responsiveness. Nevertheless, in spite of the low number of patients included, the present study was able to detect significant associations between the different joint scores as well as significant improvements in all the US scores.

\section{Conclusions}

The joints found to be most frequently inflamed in the present study are to a large extent included in the different described reduced joint combinations. All the reduced joint scores were found to have high associations to the comprehensive 78-joint score and they were sensitive to change during biological medication. Even the 7-joint score was as sensitive to change as the 78-joint score for $\mathrm{BM}$ and $\mathrm{PD}$ assessments. The optimal combination of joints and tendons to be assessed by US should be further explored to make a valid, reliable and feasible score. However, the present study supports that even low numbers of joints and tendons seem to be sufficient to reflect the response to biological treatment. 

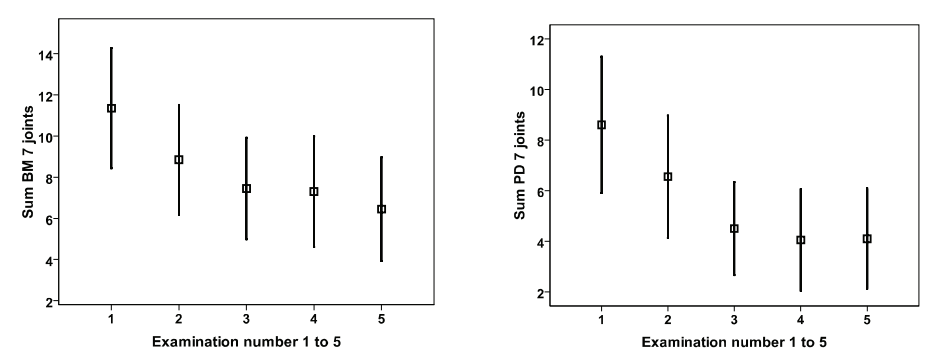

7-joint score; BM and PD
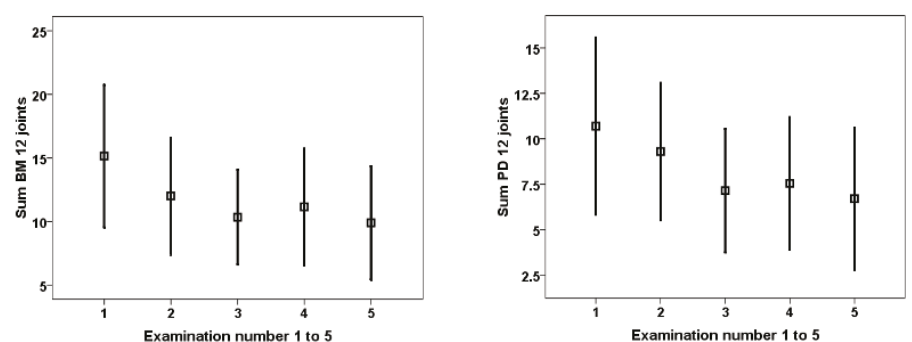

12-joint score; BM and PD
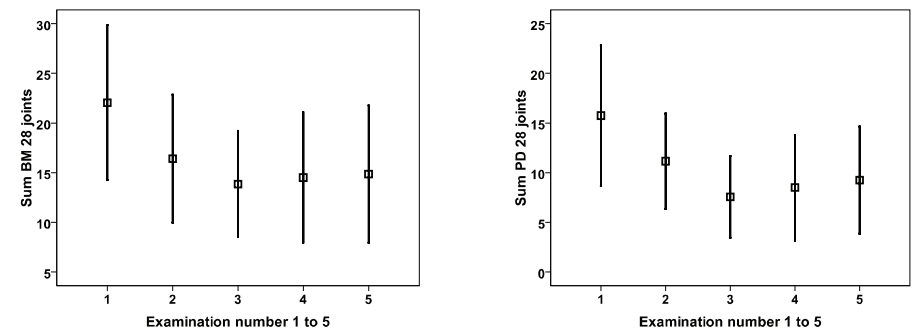

28-joint score; BM and PD
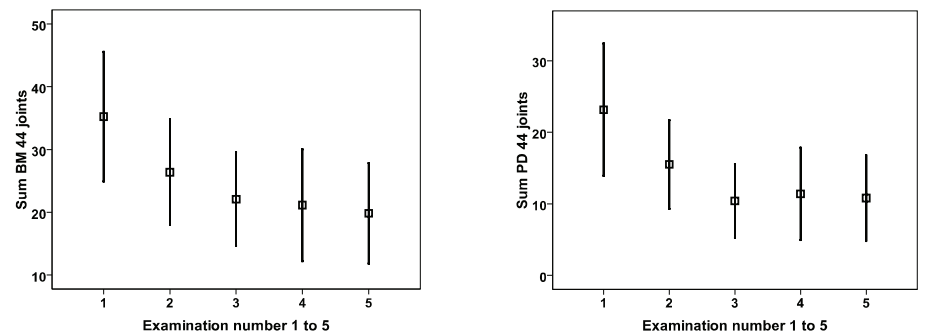

44-joint score; BM and PD
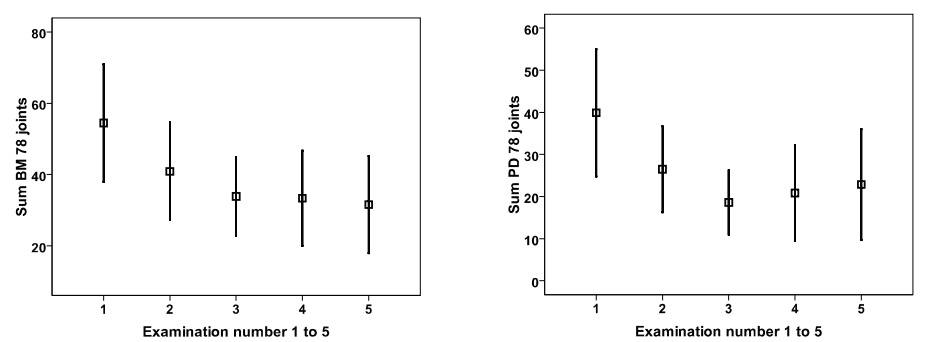

78-joint score; BM and PD

Figure 1 Error bar chart of the 7-, 12-, 28-, 44- and 78 joint scores for the mean sum BM or PD scores (with $95 \%$ confidence interval). BM; B-mode, PD; power Doppler 


\section{Abbreviations}

ACR: American Congress of Rheumatology; Anti-TNF: anti-tumor necrosis factor; BM: B-mode; Cl: confidence interval; CMC: carp-metacarpal; DAS28: disease activity score 28 joints; EULAR: European League Against

Rheumatism; IgM: immunoglobulin M; MCP: metacarpo-phalangeal; MHz: megahertz; MRI: Magnetic Resonance Imaging; MTP: metatarso-phalangeal; OMERACT: Outcome Measures in RA Clinical Trials; PD: power Doppler; PIP: proximal interphalangeal; RA: rheumatoid arthritis; US: ultrasonography

\section{Acknowledgements}

The study was supported by a grant from Abbott Norway.

\section{Authors' contributions}

$\mathrm{HBH}$ has been in charge of the conception and design, has performed all the US assessments and the analysis of the data, has been in charge of drafting the manuscript and has given final approval of the manuscript version to be published. TKK has made substantial contributions to the design of the study and interpretation of data, has revised it critically for important intellectual content and has given final approval of the version to be published.

\section{Competing interests}

The authors declare that they have no competing interests.

Received: 28 November 2010 Revised: 7 March 2011

Accepted: 27 May 2011 Published: 27 May 2011

\section{References}

1. Wakefield RJ, Balint PV, Szkudlarek M, Filippucci E, Backhaus M, D'Agostino MA, Sanchez EN, lagnocco A, Schmidt WA, Bruyn GA, Kane D, O'Connor PJ, Manger B, Joshua F, Koski J, Grassi W, Lassere MN, Swen N, Kainberger F, Klauser A, Ostergaard M, Brown AK, Machold KP, Conaghan PG: Musculoskeletal ultrasound including definitions for ultrasonographic pathology. OMERACT 7 Special Interest Group. J Rheumatol 2005, 32:2485-2487.

2. Kane D, Balint PV, Sturrock RD: Ultrasonography is superior to clinical examination in the detection and localization of knee joint effusion in rheumatoid arthritis. J Rheumatol 2003, 30:966-971.

3. Naredo E, Bonilla G, Gamero F, Uson J, Carmona L, Laffon A: Assessment of inflammatory activity in rheumatoid arthritis: a comparative study of clinical evaluation with grey scale and power Doppler ultrasonography. Ann Rheum Dis 2005, 64:375-381.

4. Szkudlarek M, Klarlund M, Narvestad E, Court-Payen M, Strandberg C, Jensen KE, Thomsen HS, Østergaard M: Ultrasonography of the metacarpophalangeal and proximal interphalangeal joints in rheumatoid arthritis: a comparison with magnetic resonance imaging, conventional radiography and clinical examination. Arthritis Res Ther 2006, 8:R52.

5. Naredo E, Möller I, Cruz A, Carmona L, Garrido J: Power Doppler ultrasonographic monitoring of response to anti-tumor necrosis factor therapy in patients with rheumatoid arthritis. Arthritis Rheum 2008, 58:2248-2256.

6. Terslev L, Torp-Pedersen S, Qvistgaard E, Kristoffersen H, Røgind $H_{\text {, }}$ Danneskiold-Samsøe B, Bliddal $\mathrm{H}$ : Effects of treatment with etanercept (Enbrel, TNRF:Fc) on rheumatoid arthritis evaluated by Doppler ultrasonography. Ann Rheum Dis 2003, 62:178-181.

7. Filippucci E, lagnocco A, Salaffi F, Cerioni A, Valesini G, Grassi W: Power Doppler sonography monitoring of synovial perfusion at the wrist joints in patients with rheumatoid arthritis treated with adalimumab. Ann Rheum Dis 2006, 65:1433-1437.

8. Iagnocco A, Filippucci E, Perella C, Ceccarelli F, Cassarà E, Alessandri C, Sabatini E, Grassi W, Valesini G: Clinical and ultrasonographic monitoring of response to adalimumab treatment in rheumatoid arthritis. Rheumatol 2008, 35:35-40.

9 Backhaus M, Ohrndorf S, Kellner H, Strunk J, Backhaus TM, Hartung W, Sattler H, Albrecht K, Kaufmann J, Becker K, Sörensen H, Meier L, Burmester GR, Schmidt WA: Evaluation of a novel 7-joint ultrasound score in daily rheumatologic practice: a pilot project. Arthritis Rheum 2009, 61:1194-1201.

10. Naredo E, Rodríguez M, Campos C, Rodríguez-Heredia JM, Medina JA, Giner E, Martínez O, Toyos FJ, Ruíz T, Ros I, Pujol M, Miquel X, García L, Aznar JJ, Chamizo E, Páez M, Morales P, Rueda A, Tuneu R, Corominas H, de
Agustín JJ, Moragues C, Mínguez D, Willisch A, González-Cruz I, Aragón A, Iglesias G, Armas C, Pablo Valdazo J, Vargas C, et al: Validity, reproducibility, and responsiveness of a twelve-joint simplified power Doppler ultrasonographic assessment of joint inflammation in rheumatoid arthritis. Arthritis Rheum 2008, 59:515-522.

11. Scirè CA, Montecucco C, Codullo V, Epis $\mathrm{O}$, Todoerti M, Caporali R: Ultrasonographic evaluation of joint involvement in early rheumatoid arthritis in clinical remission: power Doppler signal predicts short-term relapse. Rheumatology 2009, 48:1092-1007.

12. Prevoo ML, van 't Hof MA, Kuper HH, van Leeuwen MA, van de Putte LB, van Riel PL: Modified disease activity scores that include twenty-eightjoint counts. Development and validation in a prospective longitudinal study of patients with rheumatoid arthritis. Arthritis Rheum 1995, 38:44-48.

13. Jousse-Joulin S, d'Agostino MA, Marhadour T, Albert JD, Bentin J, Chary Valckenaere I, Etchepare F, Gaudin P, Hudry C, Chalès G, Grange L, Hacquard C, Loeuille D, Sellam J, Dougados M, Saraux A: Reproducibility of joint swelling assessment by sonography in patients with long-lasting rheumatoid arthritis (SEA-Repro study part II). J Rheumatol 2010, 37:938-945.

14. Hammer HB, Sveinsson M, Kongtorp AK, Kvien TK: A 78-joints ultrasonographic assessment is associated with clinical assessments and is highly responsive to improvement in a longitudinal study of patients with rheumatoid arthritis starting adalimumab treatment. Ann Rheum Dis 2010, 69:1349-1351.

15. Hammer HB, Kvien TK: Ultrasonography shows significant improvement in wrist and ankle tenosynovitis in rheumatoid arthritis patients treated with adalimumab. Scand J Rheumatol 2011, 40:178-182.

16. Haavardsholm EA, Østergaard M, Ejbjerg BJ, Kvan NP, Kvien TK: Introduction of a novel magnetic resonance imaging tenosynovitis score for rheumatoid arthritis: reliability in a multireader longitudinal study. Ann Rheum Dis 2007, 66:1216-1220.

17. Arnett FC, Edworthy SM, Bloch DA, McShane DJ, Fries JF, Cooper NS, Healey LA, Kaplan SR, Liang MH, Luthra HS, et al: The American Rheumatism Association 1987 revised criteria for the classification of rheumatoid arthritis. Arthritis Rheum 1988, 31:315-324.

18. Torp-Pedersen ST, Terslev L: Settings and artefacts relevant in colour/ power Doppler ultrasound in rheumatology. Ann Rheum Dis 2008, 67:143-149.

19. Backhaus M, Burmester GR, Gerber T, Grassi W, Machold KP, Swen WA Wakefield RJ, Manger B: Guidelines for musculoskeletal ultrasound in rheumatology. Working Group for Musculoskeletal Ultrasound in the EULAR Standing Committee on International Clinical Studies including Therapeutic Trials. Ann Rheum Dis 2001, 60:641-649.

20. Ellegaard K, Torp-Pedersen S, Henriksen M, Lund H, Danneskiold-Samsøe B, Bliddal $\mathrm{H}$ : Influence of recent exercise and skin temperature on ultrasound Doppler measurements in patients with rheumatoid arthritisan intervention study. Rheumatology 2009, 48:1520-1523.

21. Dominick KL, Jordan JM, Renner JB, Kraus VB: Relationship of radiographic and clinical variables to pinch and grip strength among individuals with osteoarthritis. Arthritis Rheum 2005, 52:1424-1430.

22. Paradowski PT, Lohmander LS, Englund M: Natural history of radiographic features of hand osteoarthritis over 10 years. Osteoarthritis Cartilage 2010, 18:917-922.

23. Aletaha D, Neogi T, Silman AJ, Funovits J, Felson DT, Bingham CO, Birnbaum NS, Burmester GR, Bykerk VP, Cohen MD, Combe B, Costenbader KH, Dougados M, Emery P, Ferraccioli G, Hazes JM, Hobbs K, Huizinga TW, Kavanaugh A, Kay J, Kvien TK, Laing T, Mease P, Ménard HA, Moreland LW, Naden RL, Pincus T, Smolen JS, StanislawskaBiernat E, Symmons D, et al: 2010 rheumatoid arthritis classification criteria: an American College of Rheumatology/European League Against Rheumatism collaborative initiative. Ann Rheum Dis 2010 69:1580-1588

24. Szkudlarek M, Court-Payen M, Jacobsen S, Klarlund M, Thomsen HS, Østergaard M: Interobserver agreement in ultrasonography of the finger and toe joints in rheumatoid arthritis. Arthritis Rheum 2003, 48:955-962.

25. Szkudlarek M, Court-Payen M, Strandberg C, Klarlund M, Klausen T, Østergaard M: Contrast-enhanced power Doppler ultrasonography of the metacarpophalangeal joints in rheumatoid arthritis. Eur Radiol 2003, 13:163-168.

26. van der Heijde DMFM, van 't Hof MA, van Riel PLCM, van Leeuwen MA, van Rijswijk MH, van de Putte LBA: Validity of single variables and composite 
indices for measuring disease activity in rheumatoid arthritis. Ann Rheum Dis 1992, 51:177-181.

27. van der Heijde DM, van 't Hof M, van Riel PL, van de Putte LB:

Development of a disease activity score based on judgment in clinical practice by rheumatologists. J Rheumatol 1993, 20:579-581.

28. Smolen JS, Breedveld FC, Schiff MH, Kalden JR, Emery P, Eberl G, van Riel PL, Tugwell P: A simplified disease activity index for rheumatoid arthritis for use in clinical practice. Rheumatology 2003, 42:244-257.

29. Aletaha D, Landewe R, Karonitsch T, Bathon J, Boers M, Bombardier C, Bombardieri S, Choi H, Combe B, Dougados M, Emery P, Gomez-Reino J, Keystone E, Koch G, Kvien TK, Martin-Mola E, Matucci-Cerinic M, Michaud K, O'Dell J, Paulus H, Pincus T, Richards P, Simon L, Siegel J, Smolen JS, Sokka T, Strand V, Tugwell P, van der Heijde D, van Riel P, et al: Reporting disease activity in clinical trials of patients with rheumatoid arthritis: EULAR/ACR collaborative recommendations. Ann Rheum Dis 2008, 67:1360-1364

30. Knevel R, Schoels M, Huizinga TW, Aletaha D, Burmester GR, Combe B, Landewé RB, Smolen JS, Sokka T, van der Heijde DM: Current evidence for a strategic approach to the management of rheumatoid arthritis with disease-modifying antirheumatic drugs: a systematic literature review informing the EULAR recommendations for the management of rheumatoid arthritis. Ann Rheum Dis 2010, 69:987-994.

31. Brown AK, Quinn MA, Karim Z, Conaghan PG, Peterfy CG, Hensor E, Wakefield RJ, O'Connor PJ, Emery P: Presence of significant synovitis in rheumatoid arthritis patients with disease-modifying antirheumatic drug-induced clinical remission: evidence from an imaging study may explain structural progression. Arthritis Rheum 2006, 54:3761-3773.

doi:10.1186/ar3341

Cite this article as: Hammer and Kvien: Comparisons of 7- to 78-joint ultrasonography scores: all different joint combinations show equal response to adalimumab treatment in patients with rheumatoid arthritis. Arthritis Research \& Therapy 2011 13:R78.

\section{Submit your next manuscript to BioMed Central and take full advantage of:}

- Convenient online submission

- Thorough peer review

- No space constraints or color figure charges

- Immediate publication on acceptance

- Inclusion in PubMed, CAS, Scopus and Google Scholar

- Research which is freely available for redistribution

Submit your manuscript at www.biomedcentral.com/submit 